\title{
'WELL, THEY'RE VERY GOOD CITIZENS': NEW ZEALANDERS' PERCEPTIONS OF ASIANS IN NEW ZEALAND
}

\author{
Andrew Butcher
}

\begin{abstract}
Drawing on the Asia New Zealand Foundation's tracking studies of New Zealanders' perceptions of Asia, this article examines how these perceptions have changed over time and what the characteristics of these perceptions are, in terms of geography and age. Particular attention is given to changing perceptions vis-à-vis the diversifying ethnic composition of New Zealand's population, both during the period of the tracking study, and through forward demographic projections. Inevitably, changes to New Zealand's population provoke questions about New Zealand's national identity and the place of Asians within that, and this article concludes by asking to what extent Asians will be involved in the 'making of New Zealand' in the twenty-first century. ${ }^{1}$
\end{abstract}

\section{INTRODUCTION}

New Zealand is a classic immigrant-receiving society but the demographic changes that have occurred in New Zealand are unique for the speed with which they have occurred. New Zealand's population has changed rapidly in a very short period of time. In a period of less than 50 years, New Zealand society has transformed from a relatively homogeneous one to a society now marked by significant heterogeneity. Not only has New Zealand's range of ethnic and immigrant groups increased, but so have the numbers of overseasborn as a proportion of New Zealand's total population, putting New Zealand ahead of Canada and only slightly behind Australia in this (Gendall, Spoonley and Trlin 2007:10).

New Zealand's previous immigration practices favoured immigrants from Europe, particularly if they had British origins. This remained until major immigration policy changes in 1986, although Pacific populations were brought in to New Zealand in the 1970s because of labour shortages, and Asian refugees also 
entered New Zealand during this time. Since 1987 there has been a significant increase in Asian migrants. Most of the Asians who lived in New Zealand by the 2006 Census had arrived after 1987 (Friesen 2008:3). Depending on how figures are calculated, Auckland now has a higher overseas-born percentage of population than any other city in New Zealand and Australia (Spoonley, Gendall and Trlin 2007:3; cf. Friesen 2008). New Zealand also has significant and growing economic links with Asia, and immigrants are now critical to New Zealand's economic development (Spoonley et al 2007:3).

This article first surveys New Zealanders' perceptions of Asians, conceptually and within the broader research programme on Asians in New Zealand generally, before detailing Asia New Zealand Foundation's (Asia:NZ) 2007 Perceptions of Asia survey (Colmar Brunton 2007). The article then analyses statistical data from the 2006 Census, with particular reference to the actual and projected characteristics of New Zealand's Asian populations. The paper concludes by examining the implications of this changing identity on New Zealanders' perceptions of Asia and on what it means to be a New Zealander more generally.

NEW ZEALAND AS A UNIQUE SETTLER SOCIETY

While New Zealand shares its settler society origins along with Canada and Australia (see Pearson 2001), it is unique with respect to its bicultural framework (Fleras and Spoonley 1999). Where New Zealand has followed these and other countries, is in adopting social cohesion as a policy position across a range of government departments ${ }^{2}$ (see Spoonley, Peace, Butcher and O'Neill 2005), driven in part by New Zealand's growing immigrant, especially Asian populations. Implicit in the drive toward social cohesion is the rationale that the lack of integration of migrants into New Zealand will have socially divisive effects.

For that reason, this paper devotes considerable space to describing New Zealand's demographic data. New Zealanders' attitudes towards immigrants generally, and Asians in particular, need to be seen within the specific realities of a rapidly diversifying population. It is not, of course, that anti-Asian sentiment, for example, is a phenomenon attributable only to growing Asian populations; it was part of New Zealand's response to the very first Asian settlers to New Zealand in the nineteenth century. But, as the Asian population in New Zealand is predicted to grow to a proportion the same as or greater than other minority ethnic populations in New Zealand, including Maori, there is a need to locate this with New Zealanders' attitudes toward Asians and data about the 
growing Asian populations in New Zealand. Some research reports in New Zealand have expressed New Zealanders' concern that while immigrants are welcome in New Zealand society, it is preferred that they come from AngloCeltic origins (Ward and Masgoret 2008:241) and are not Muslim (Butcher, Spoonley and Trlin 2006:29-30, 40).

Two relevant issues to this paper flow from this. First, there is still a common perception among the general New Zealand population that the Asian population in New Zealand are migrants, without recognition that Asians in New Zealand may be New Zealand-born (see Ip 1996; Leckie 2007), or may have New Zealand citizenship or residence. Related to this, there is little understanding among the general public of the diversity of New Zealand's 'Asian' populations. This is a point forcefully made in two significant publications twelve years apart. The first publication in the mid-199os, by long-established New Zealanders of Asian origin, Vasil and Yoon (1996:11-12, quoted in Bedford and Ho 2008:1), noted:

it is important to recognise that even though today migrants from Asia represent almost all countries of the continent they do not (and are not likely to in the future) constitute an Asian community. Sharp inter-ethnic divisions among many of them, especially the Chinese and the Indian ethnic groups, make it extremely difficult even for individual ethnic groups to unite and develop a strong sense of community. Immigrants from Asia will never be in a position to threaten the paramountcy of the Pakeha and the primacy of their values, language, culture and way of life. As such, New Zealanders have little to fear from their presence in New Zealand, even in terms of their fast increasing numbers.

Bedford and Ho (2008:1) emphasised Yasil and Yoon's warning:

...about the irrelevance of a label of Asian for peoples with cultural links to a vast region stretching from the Middle East to Japan that Europeans have labelled as Asia, it remains common practice in New Zealand to refer to the country's Asian population as an entity.

The term 'Asian' is in many ways significantly meaningless, possibly useful for geographers, but highly deficient as a descriptor of peoples from twenty-seven countries. Nonetheless, whatever its gross deficiencies, New Zealanders do not, as discussed below, easily distinguish between an Asian of one ethnicity or birthplace from another Asian of a different ethnicity or birthplace. In 
New Zealand's public discourse 'Asian' is a catch-all term, albeit inadequate, but because of its common usage alone, is useful when considering New Zealanders' perceptions of Asian peoples in New Zealand. The term 'Asian' is still relevant to use vis-à-vis the term 'New Zealander'. Increasingly the two terms are adjoined, where Asians who are born in New Zealand might self-describe as 'Asian New Zealanders' but at the level of public discourse, it can be convincingly argued that the general public, most media outlets and politicians do not primarily see 'Asians' as subsumed within the term 'New Zealander'. This article treats these terms as two distinct groups, even if that is not so in reality. Perceptions of Asians in New Zealand are not driven nor persuaded by facts. A more provocative and compelling illustration of Asians in New Zealand can be seen by the general public, by those who are not Asian at least, in the various and growing Asian ethnoscapes in New Zealand's largest cities (Friesen 2008). New Zealand's cityscapes are changing along with its demography and although those changes began over a century ago, the reality is that for most New Zealanders 'Asian' is synonymous with 'migrant' and therefore is not synonymous with 'New Zealander'.

Secondly, questions around perceptions of Asians in New Zealand imply notions of whether Asians are seen, by themselves and others, to 'belong'; and whether they are 'being accepted' (Butcher, Spoonley and Trlin 2006). Vasta (2007:26) suggests that a sense of belonging, in the form of social cohesion, can be engineered, beginning with mutual accommodation; part of an 'expanded multiculturalism' (Vasta 2007:27). Vasta also notes a sense of belonging working both ways (Vasta 2007:34). The repetition of research that identifies discrimination against migrant populations, particularly those that are not Anglo-Celtic in origin, would suggest that there is far from a sense of belonging by minority ethnic groups in New Zealand, as outlined below.

New Zealanders' perceptions of Asians matter, both in their own right, with respect to Asians becoming an integral part of New Zealand society, but also because of the increasing number of Asians who will be born in or migrate to New Zealand. They matter not only for the purposes of belonging to a minority ethnic group, but also for notions of nationhood in New Zealand. If a growing proportion of New Zealand's population are not seen as beneficial in their own right, or are only seen as beneficial where they adopt the values and cultures of the majority ethnic group (Pakeha), or where they do not threaten the tangata whenua of Maori, then the very notions of what it means to be a New Zealander are thrown into disarray. New Zealand, unlike Australia, does not have an official multicultural policy and, even if it did, would an 'expanded multi- 
culturalism, as posed by Vasta (2007), really work, particularly when placed alongside, above or below New Zealand's unique bicultural framework?

As discussed below, while, at face value, New Zealanders' perceptions of Asians are not becoming more negative over time, they are not becoming more positive. There are nuances within survey data that suggest that there are pockets of resistance toward New Zealand's growing Asian populations. Policy discussions around 'social cohesion' are sufficient if the only expectation upon the host society is to provide the services and resources to aid integration of migrants, for example, without the host culture also adapting their own values to at least accommodate those of its various ethnic groups. This could be the supposition from the person who described Asians as, 'well, they're very good citizens' in Asia:NZ's Perceptions of Asia study (Colmar Brunton 2007: 25). Maybe this person implied 'good citizens' as in following the law, behaving politely, etc. but perhaps they also meant 'good citizens' as in not upsetting the majority culture's sense of itself, its world view, and its notion of what it means to be in New Zealand and to be a 'New Zealander', by integrating into a 'New Zealand' way of life, and adopting 'New Zealand' values and customs.

To this extent, local attitudes play an important and significant role. Attitudes among gatekeepers in employment, accommodation and healthcare are key (see Butcher et al 2006) but also broad public understanding and attitudes are important. Opinion surveys on public attitudes toward migrants indicate who is welcome and the nature of the welcome of immigrants; issues critical to a nation-building project with a rapidly diversifying society (Spoonley et al 2007). Immigrants are often considered outsiders; a categorisation also made by those that may not be immigrants but who may appear differently to the majority host community (Henderson, Trlin and Watts 2006). There is an expectation that migrants, newcomers, or those who are in other ways ethnically or culturally different, will adapt to the 'ways of life' of the majority culture, without the majority culture required to make adjustments themselves (see Li 2003; Favell 2001). Surveys indicate that New Zealanders prefer migrant groups that speak English and have a British heritage (e.g. Ward and Masgoret 2008; Henderson et al 2006).

\section{LITERATURE REVIEW}

From 'drug-besotten, sin-begotten fiends of filth' (Moloughney and Stenhouse 1999) to the 'model minority' (see Ip 2003) to an 'Asian Invasion' (Spoonley 1990; Spoonley and Trlin 2004), to Asian criminals who bring murder, extor- 
tion, kidnapping, assassinations and disease (Coddington 2006; cf. Spoonley et al 2007), Asian communities have been represented in a number of significant and negative ways. Even from their earliest days of settlement in New Zealand, Indian and Chinese settlers were subject to racist legislative practices (Leckie 1995; Ip and Pang 2005).

There is an extensive body of micro-level quantitative research on experiences concerning Asian migrants in New Zealand. For research on skilled Asian immigrants, business migrants or entrepreneurs, a dominant theme has been the difficulty of finding employment when faced by prejudice and discrimination (e.g. Basnayake 1999; Henderson 2003; Ho and Lidgard 1998; Ho, Bedford and Goodwin 1999; Ho, Bedford and Bedford 2000; Lal 1998; Lidgard 1996; Lidgard and Yoon 1999). From this perspective, the problems experienced by Asian immigrants in Auckland since the early 1990 os (e.g. Boyer 1996; Friesen and Ip 1997; Henderson, Trlin and Watts 2001; Ho and Lidgard 1998; Lidgard and Yoon 1999) suggest that surprisingly little appears to have changed with respect to public attitudes and behaviour during the last century (Butcher et al 2006).

This literature contains an extensive body of research measuring New Zealanders' perceptions of Asians, immigrants and immigration (Asia 2000 Foundation 2003; Asia New Zealand Foundation 2006; Butcher et al 2006; Colmar Brunton 2007; Gendall et al 2007; Human Rights Commission 2003; Spoonley et al 2007). The National Business Review has conducted surveys since the early 199 os on New Zealanders' attitudes to migrants (see Trlin et al 1998; Liu 2005). Fewer studies have measured perceptions of Asians specifically. These various surveys have indicated a strong negative feeling toward immigrants, and particularly Asians during most of the 1990s, bolstered by the election campaign of the political party, New Zealand First in 1996, that was reinforced by media portrayals at this time (see Spoonley and Trlin 2004). ${ }^{3}$ There is an apparent correlation between the high number of immigrants and negative attitudes toward migration, and low numbers of immigrants and positive attitudes to migration (Spoonley et al 2007).

In the summary of recent research on discrimination in New Zealand by the Human Rights Commission and the Asia 2000 Foundation, Butcher et al (2006:9) found that the key shift since a similar survey in 2001 was that Asians are more likely to be identified as the targets of discrimination. In 2001 fourteen percent of respondents identified which groups they thought were generally most discriminated against and this increased to twenty-eight percent in 2003. When survey participants were asked whether there was a 'great deal', 
'some,' 'only a little' or 'no discrimination' against a list of groups, it was established that Asians, recent immigrants and refugees were the top three groups against which participants thought there was a 'great deal' and 'some' discrimination. International surveys indicate that certain demographic characteristics are particularly associated with attitudes toward immigrants and immigration, especially ethnicity and education. Those who share the characteristics of being ethnically different from the mainstream are more likely to feel sympathy for immigrants who are seen as different (Spoonley et al 2007:5).

Gendall et al (2007), comparing two surveys measuring New Zealanders' attitudes to immigrants and immigration in 2003 and 2006 (see Spoonley et al 2007; cf. Butcher et al 2006: v), note contradictory findings. In 2006 more respondents reported hearing racist remarks about immigrants than in 2003 while more respondents in 2006 considered that the number of immigrants to New Zealand should be increased or remain the same. Against this, there was also some evidence of a hardening of attitudes, particularly around immigrants adopting New Zealand traditions and customs (Butcher et al 2006:18-19). They also noted the attitudes of Aucklanders were more negative than elsewhere in New Zealand (cf. Colmar Brunton 2007; Friesen 2008), and that younger people and Maori tended to be less tolerant of immigrants than older people and non-Maori (Butcher et al 2006: v-vi). The former finding is counter-intuitive, though some evidence of similar findings is emerging elsewhere (Colmar Brunton 2007: 29); while the latter finding may indicate that Maori recognise their vulnerability in competing with immigrants for employment opportunities and the threat that immigrants may bring to New Zealand's bicultural framework (cf. New Zealand First 2008). Gendall et al (2007:32-33) also identify an issue considered later in this paper: the mix of attitudes toward migrants is such that, given adverse economic conditions, migrants might once again find themselves the victims of anti-immigration politics and racism.

TRACKING STUDIES OF NEW ZEALANDERS' PERCEPTIONS OF ASIA

Alongside these academic-based surveys, Asia:NZ has undertaken a series of tracking studies of New Zealanders' perceptions of Asia. In 1997, Asia:NZ ${ }^{4}$ began a series of tracking studies measuring New Zealanders' perceptions of Asia (Asia 2000 Foundation 2003; Asia:NZ 2006; Colmar Brunton 2007). These surveys differ from surveys conducted by the Human Rights Commission, which measure discrimination, and from Massey University surveys (e.g. Gendall et al 2003), which measure attitudes toward immigrants: the distinction is that Asia:NZ's surveys measure attitudes toward Asians, whether they 
are immigrants or not and whether they are discriminated against or not. Nine studies have occurred since 1997 (twice in 1998 (April and November), April 1999, April 2000, April 2002, February 2004, April 2006 and November 2007) with a further study due at the end of 2008 and further studies planned every year thereafter. There are minor differences in the types of questions asked between the 1997-2006 surveys and the 2007 survey, so trends need to be read with some caution. This article is particularly concerned with the 2007 survey, although, where appropriate, refers back to previous tracking studies.

The surveys from 1998 until 2006 measured: the perceived importance of specific regions of the world to New Zealand's future; ${ }^{5}$ the level of personal involvement with Asian peoples or cultures; interest in specific Asian issues; and views of Asian involvement in New Zealand. Except for some small-scale analysis by Beal (2006) and Butcher et al (2006), this is the first time Asia:NZ's tracking studies of New Zealanders' perceptions of Asia have been analysed in this way.

\section{Methodology}

For the 2007 survey, Computer Assisted Telephone Interviews (CATI) were conducted with a random sample of $1001 \mathrm{New}$ Zealanders aged fifteen or over. These data were weighted by household size (defined as the number of people fifteen and over who live in the household). Percentages were therefore postweighted by age and gender to ensure that overall results represent the New Zealand population on these key variables. The results had a margin of error of $+/-3.1$ percent at the 95 percent confidence level.

The 2007 questionnaire was adapted from previous versions of the tracking study questionnaires and was designed by Colmar Brunton in consultation with Asia:NZ. The first three questions were designed to gain an understanding of New Zealanders' conceptions of Asia, and to measure feelings of warmth toward the country first mentioned by each respondent. From that point on, respondents were asked to think about Asia as a whole.

From 2007, the survey was expanded to include questions on: the perceived importance of Asia to New Zealand's future (which had previously only been asked of those who had indicated that Asia was the most important region), with specific reference to exports from New Zealand to Asia; Asian tourism in New Zealand; the economic growth of the Asian region; Asia as a tourist destination for New Zealanders; Asian cultures and traditions; imports from Asia to New Zealand; immigration from Asia to New Zealand, and the population 
growth of the Asian region; the concept of Asia to New Zealanders ('when you think of Asia, which countries come to mind?'); points of contact with Asian people (whereas previous studies had asked only about the level of contact); perceptions of warmth or coolness towards Asian people (demonstrated in the report using a thermometer), and reasons for these feelings of warmth or coolness; the perceived contributions of Asian peoples to New Zealand (with specific reference to the economy, cultural diversity and workplace productivity); and perceptions of Asian people on likeability and competence. Further detailed statistical analysis was undertaken to establish variables about the sample population (including gender, age, ethnicity, location and occupation as a proxy for socioeconomic status, using the New Zealand socio-economic index).

\section{Findings}

In 2007, 71 percent of New Zealanders continued to see the Asia region as important to New Zealand's future, which was generally consistent with previous studies. However, there had been a significant increase in New Zealanders seeing Asia as an important export market: to 90 percent in 2007 from 73 percent of New Zealanders who were positive about trade between Asia and New Zealand in 2006 (whereas when asked about why the Asian region was important, in 2006, 25.3 percent saw it as important). New Zealanders who felt that Asia's economic growth would have a positive impact on New Zealand's future had also increased to a significant 77 percent. (In 2006, across the related questions, 46.6 percent of respondents saw the Asian region as important for trade market/opportunities; the growth and potential of the Asian region at 22.6 percent; good for business, 18.7 percent; wealthy region, 10.3 percent; and contact with Asia's large economies, 3.4 percent).

Asian tourism to New Zealand was seen by 90 percent of New Zealanders as having a positive impact while 78 percent indicated that tourism to Asia would have a positive impact on New Zealand. (We can contrast this finding with 6.4 percent of New Zealanders who saw tourism as one of the reasons the Asian region is important to New Zealand in 2006 and 73 percent who had a positive view of Asian tourism to New Zealand in 2006, which has remained largely consistent since 1997). There was also a small increase of New Zealanders who had 'a lot' or 'a fair amount' of contact with people from Asia: from 44 percent in 2006 to 48 percent in 2007 (there has been a steady increase from 30 percent in 1998 to 34 percent in 2002 to 38 percent in 2004). Asian immigration in New Zealand was viewed by only 38 percent of New Zealanders as being positive in 2006 (up to that point, from 1998, there was an average of about 
32 percent of New Zealanders who felt that way); whereas in 2007,76 percent of New Zealanders agreed that Asian immigrants brought cultural diversity to New Zealand.

Of questions not previously asked in the tracking survey, when New Zealanders think of Asia, they tend to think initially about China (51 percent) or Japan (20 percent); New Zealanders' primary points of contact with Asian people included through work or business (66 percent), friends (65 percent), neighbourhood or community (59 percent), or through schools or educational institutions ( 51 percent). Nearly half (49 percent) of all New Zealanders have had at least some contact with Asian people through clubs or social events. New Zealanders also tended to perceive Asian people as competent and hardworking. New Zealanders were warmest toward people from Thailand (mean $=82)$, Singapore $($ mean $=80)$ and India $($ mean $=79)$. New Zealanders felt less warm toward people from China $($ mean $=68)$.

Further analysis of the 2007 survey results showed that there was some ambivalence among New Zealanders about the benefits of closer relationships with Asian peoples and cultures. The majority of New Zealanders saw the key benefits for New Zealand as economic benefits: Asia is seen positively as an export market and as a region for inbound tourism to New Zealand. The majority of New Zealanders were also positive about Asia as a tourist destination for New Zealanders. Overall, New Zealanders were less positive about the impact of imported goods from Asia compared to the impact of exporting goods to Asia. New Zealanders were also less positive about the impact of Asian cultures, traditions and immigration on New Zealand's future: four out of ten New Zealanders did not think Asian cultures and traditions would have a positive impact on New Zealand's future, and a quarter of New Zealanders believed Asian immigration would have a negative impact on New Zealand's future.

The findings clearly demonstrate that increasing contact with Asian people is associated with more positive perceptions of, and warmer feelings toward, Asian people. New Zealanders with the most contact with Asian people were more likely to agree that Asian people bring valuable cultural diversity to New Zealand, and were more likely to describe Asian people as nice, friendly and warm. By contrast, New Zealanders who had little or no contact with Asian people were more likely to perceive Asian people as unlikeable.

Colmar Brunton undertook further analysis on the basis of age and specific findings were: 
- Respondents under 20 were less likely than older respondents to agree that Asian immigrants bring valuable cultural diversity to New Zealand (see also Spoonley et al, 2007; Gendall et al, 2007).

- Respondents under the age of 50 were less likely than older respondents to agree that workplace productivity is improved by Asian people.

- Respondents over 60 scored Asian people more highly on competence than younger respondents.

Further analysis was undertaken about the relationship between those who hold negative views about immigration and negative views about imports from Asia. This analysis demonstrated that while there is correlation between these two variables, this correlation is not as strong as we anticipated. Colmar Brunton could claim however, that a person's perception on the impact of immigration is the strongest predictor on the impact of other questions asked in the survey. Those who saw immigration in negative terms were more likely to perceive other factors relating to Asia and Asians in negative terms also. Decreasing the number of those who are concerned about immigration could also affect other judgments.

That increasing contact with Asians leads to more positive perceptions of Asians is not unsurprising; it reflects the findings of other sociological studies (cf. Crawley 2005; Spoonley et al 2007). We may infer that New Zealanders' positive perceptions of Asia are primarily derived from personal contact, as opposed to being, for example, derived from the media. This 2007 survey also shows that urban population centres with greater numbers of Asians return more favourable perceptions than more rural or provincial centres with smaller Asian populations. It seems worthwhile to explore whether the increasing Asian population is being reflected, either positively or negatively, in New Zealanders' perceptions of Asia and Asian peoples.

THE ASIAN POPULATIONS IN NEW ZEALAND: 1991-2006

To begin, the Asian and New Zealand populations across the four censuses 1991, 1996, 2001 and 2006 are considered. 1991 data provide a snapshot of New Zealand's Asian population before Asia:NZ was established and the tracking survey began. Data from 1996 came only two years after Asia:NZ was established, while 2001 and 2006 data are of years covered by the tracking study and the development of Asia:NZ. ${ }^{6}$

As can be seen in Figure 1 (over), as New Zealand's population has increased from just under 3.5 million in 1991 to just over 4 million in 2006, the popula- 


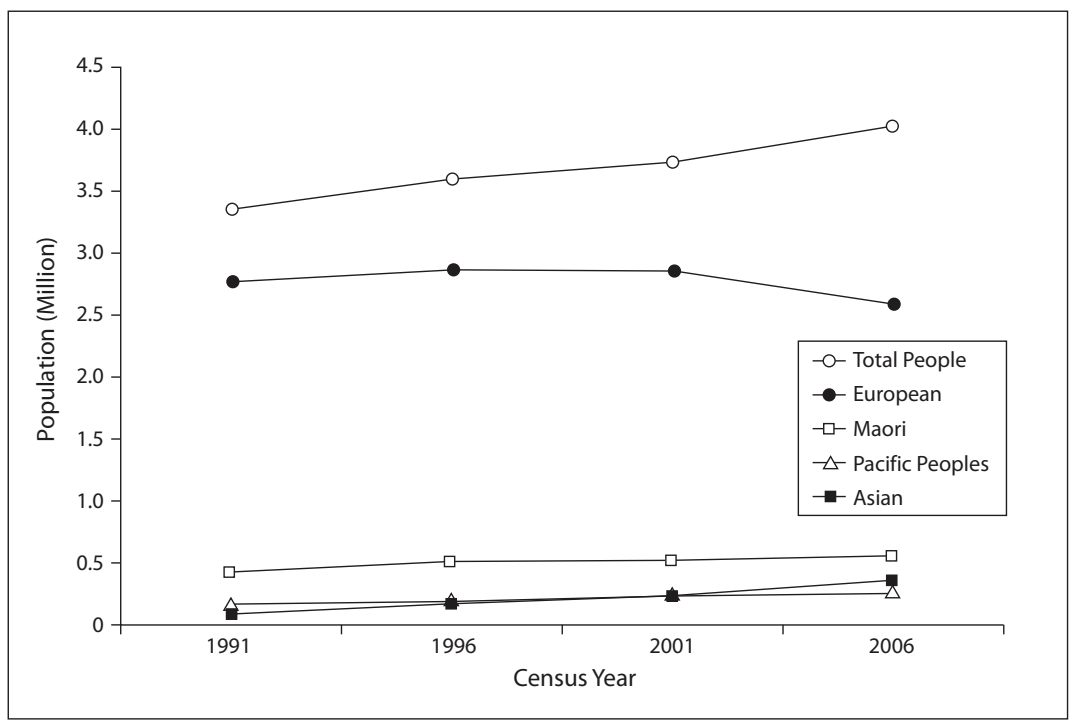

Figure 1: New Zealand's changing population 1991-2006 ${ }^{7}$

tion that identifies with the ethnic group 'European' has remained static or declined, Maori and Pacific peoples have had small increases, while Asians have increased significantly, from a population of 99,759 in 2001 to a population of 374,549 in 2006. Figure 2 shows this change as a percentage of New Zealand's total population over this same period.

The European population as a percentage of New Zealand's total population has decreased 17 percent between 1991 and 2006, while the Asian population, by contrast, has increased over 5 percent in the same period, from 3 percent of New Zealand's population in 1991 to 9 percent in 2006.

Many minority ethnic populations are making up a growing proportion of the overall New Zealand population. This reflects past and likely future differentials in fertility, as well as the impact of intermarriage and changes in migration patterns. Additionally, Maori, Asian and Pacific populations have a more youthful age structure and therefore a greater momentum for growth than the 'European' or 'Other's population. Combined with higher fertility for Maori and Pacific people, and the assumed net migration levels for Asian people, these ethnic populations are likely to grow at a much faster pace than their 'European' or 'Other' counterparts. 


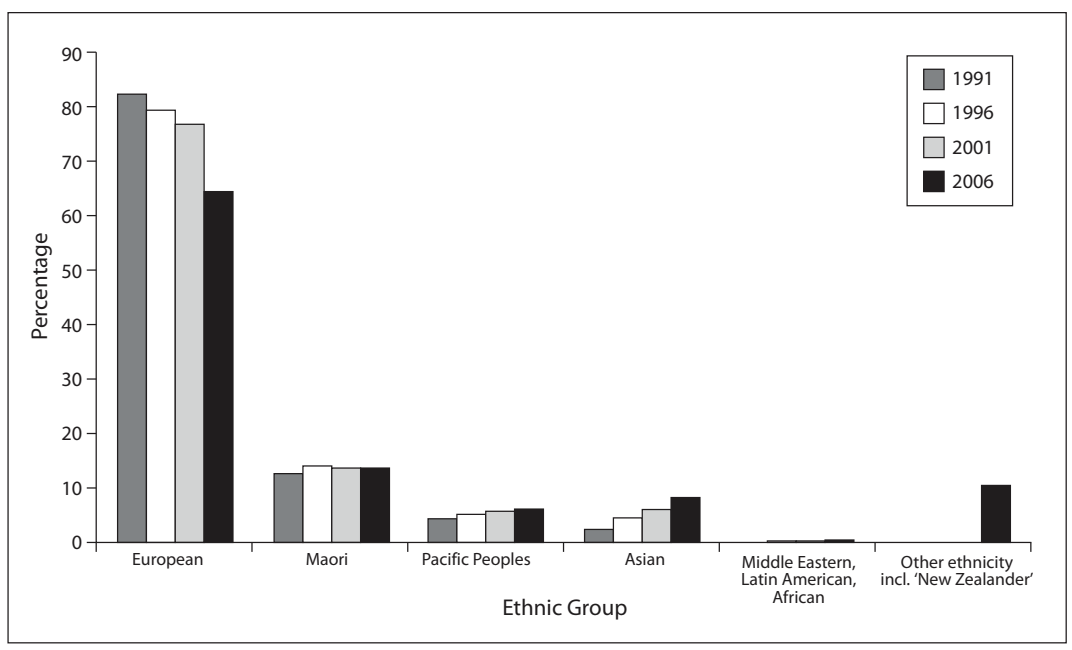

Figure 2: Ethnic populations as a percentage of New Zealand's total population 1991-2006

At the 2006 Census, the number identifying with various Asian ethnicities was: Chinese (including Taiwanese, etc) 147,570; Indian (including Fijian Indian, etc) 104,583; Korean 30,792; Filipino 16,938; Japanese 11,910; Sri Lankan (including Sinhalese, etc) 8,310; Cambodian 6,918; Thai 6,057; Vietnamese 4,773; Malay 3,540; Indonesian 3,261 and other Asian groups 13,674. There were 3,867 people who identified with more than one Asian ethnicity (eg Chinese and Indian). Of the 354,552 Asian people, 9 percent $(32,097)$ also identified with non-Asian ethnicities. While 20 percent $(70,650)$ of people who stated a birthplace were born in New Zealand, 68 percent $(240,537)$ were born in Asia.

In 2006, about 10 percent of the New Zealand population identified with more than one broad ethnic group (compared with 8 percent of New Zealand's Asian population), and this was especially the case for those under fifteen years of age. Nearly 20 percent, or one in five, of those under fifteen years of age identified with more than one ethnic group (cf. Bedford and Ho 2008; Friesen 2008). This group, of people who identify with more than one ethnic group, will inevitably constitute a larger proportion of New Zealand's population in the future: those under fifteen years of age will become older, marry and have children who may also identify with more than one ethnic group; and with an increased rate of cross-cultural marriage (Callister et al 2005), their children may identify with more than one ethnic group. 
These data provoke questions about New Zealand's identity and what constitutes a New Zealander. They also require the separation of perceptions of who is an Asian migrant and who is an Asian New Zealander (i.e. born in New Zealand), which, given they will appear similar, will not be a distinction that will be easily or frequently made. A consequence could be that should levels of discrimination against New Zealand's Asian migrants increase, discrimination could extend to New Zealand's Asian communities generally. This returns to one of the points that began this article: New Zealanders generally do not distinguish between one Asian and another, either in terms of their diverse birthplaces or in terms of whether they are New Zealand-born or a migrant. Discrimination against Asians in New Zealand, therefore, will not discriminate between one type of Asian and another type of Asian because, generally New Zealanders, and particularly the media, do not make that distinction.

Within the Asian population that migrate to New Zealand, there have been significant shifts between the 1996 and 2006 censuses for migrants from particular birthplaces. The top five birthplaces from the Asian region represented in the 2006 Census were, in descending order: the People's Republic of China $(78,117)$; India (43,341); Republic of Korea $(28,806)$; Philippines $(15,282)$ and Malaysia $(14,547)$. The growth in the New Zealand population born in these countries between 1996 and 2006 can be seen in Figure 3 .

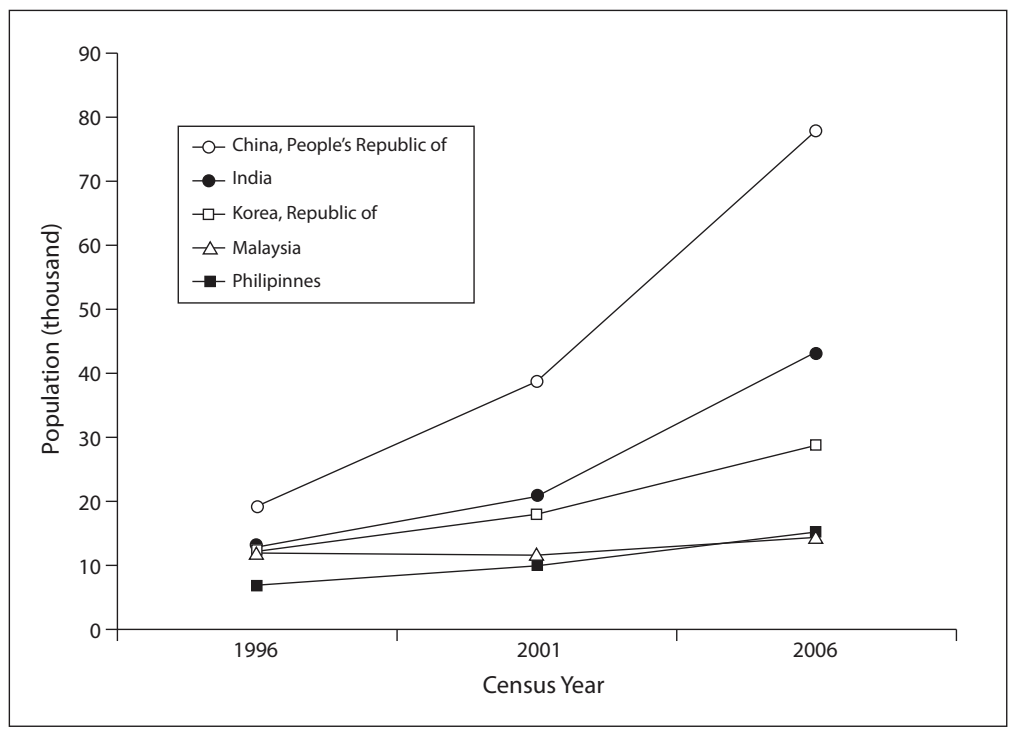

Figure 3: Top five birthplaces of New Zealand's Asia-born population, 1996-2006 
In contrast, the top five birthplaces for New Zealand's population at the 1996 Census were: the People's Republic of China (19,518); Republic of Korea $(12,183)$; India (12,807); Malaysia $(11,889)$ and Hong Kong $(11,760)$. The growth of the Philippines population is remarkable: the New Zealand population born in the Philippines went from 7,005 in 1996 to 15,282 in 2006. This is an increase of 46 percent in ten years compared to only a 25 percent increase in the population born in China. The decrease of the population born in Hong Kong (from 11,760 in 1996 to 7,683 in 2006) may be attributed to migrants from Hong Kong returning there after the handover from British to Chinese rule, which may have also been the initial reason for their departure from Hong Kong.

PROJECTED ASIAN POPULATION IN NEW ZEALAND AND ITS IMPLICATIONS

Following each census, Statistics New Zealand produces projections of New Zealand's population. The projections provide indications of possible changes in New Zealand's populations and are based on a number of assumptions formulated from an assessment of both short- and long-term demographic trends using different combinations of assumptions on fertility, mortality, migration and inter-ethnic mobility. Among the projections, Series 1 uses low population growth assumptions and projects the lowest population throughout the projection period. In contrast, Series 11 uses high population growth assumptions and projects the highest population throughout the projection period. At the time of the release of their projections from the 2006 Census, Statistics New Zealand (2008) considered the mid-point, Series 6, the most suitable for assessing future population changes.

Using their reported Series 6 projections, Statistics New Zealand projected that the Asian population will constitute 16 percent of New Zealand's total population by 2026, while the European or Other ethnicity will decrease to 69 percent in the same period (Statistics New Zealand, 2008). In a thirty-five year period, therefore, the Asian population could possibly increase by 13 percent, while the European population could possibly decrease by approximately the same percentage during the same period. These projections, which are conservative estimates, are dependent on a number of factors, including New Zealand's immigration policies, but it is worth noting that natural increase in the Asian population is projected to account for about 160 ,000 more Asians by 2026. A growing and significant proportion of New Zealand's Asian population will be born here. Even at the 2006 Census, nearly 20 percent of the Chinese and Indian populations in Auckland were born in New Zealand (Friesen 2008:4). 
Natural increase is projected to grow from 6,000 in 2007 to nearly 9,000 in 2018 , but then ease to 8,000 in 2026 . Unlike the other ethnic groups, natural increase makes a smaller contribution than net migration to Asian population growth. Nevertheless, under all scenarios Asian natural increase remains positive, ranging between 4,000 (Series 1) and 13,000 (Series 11) in 2026. The Asian population will continue to have a younger age structure than the overall New Zealand population, mainly because of immigration. Half of the Asian population will be older than 35.9 years by 2026 , compared with a median age of 28.5 years in 2006 (Series 6).

\section{ASIANS AND THE MAKING OF NEW ZEALAND}

Asia:NZ's tracking study shows that of the Asian groups mentioned, the survey respondents are less 'warm' toward China than other countries, by quite some margin (68 degrees warmth), after Thailand (82), Singapore (80), India (79), Malaysia (75) and Japan (75) (Colmar Brunton 2007). Notably, with the exception of India and Malaysia, the other countries in this list do not feature amongst the top five birthplaces of Asians in New Zealand in 2006. In fact, the populations born in Singapore and Thailand are among the smallest Asia-born populations in New Zealand in 2006 (at 4,857 and 4,614 respectively; the next and last three smallest Asia-born populations are from Pakistan, Afghanistan and Bangladesh respectively).

To some extent, it could be said that the warmth toward particular Asian populations in New Zealand is reversely proportional to the actual size of those Asian populations in New Zealand. Given that the Perceptions of Asia (Colmar Brunton 2007) study noted that New Zealanders derive their perceptions of Asia primarily through some level of personal contact, it could be inferred that while generally New Zealanders are more positive about 'Asia' as they have more contact with Asians, this does not extend to particular Asian nationalities. However, the survey judged New Zealanders' warmth towards countries they first mentioned when they thought of Asia, which were dominated by China (at 87 percent) and Japan (at 67 percent).

Furthermore, we can say with some confidence that New Zealanders probably do not make a distinction between an Asian from one Asian country and another (unless they are from South Asia as opposed to China, for example), but nor can we absolutely say that as the Asian population in New Zealand increases (which it is projected to do), New Zealanders' perceptions of that population will become increasingly more positive. Indeed, the opposite could 
be true. To use China as an example, it was the first country New Zealanders identified when they were asked to think of Asia; it has the highest proportion of Asia-born migrants in New Zealand; and it is the country towards which New Zealanders feel least warm. The perceptions of Asia and Asians by New Zealanders are far more complex and nuanced than they might first appear and indeed may not be wholly positive.

The extent to which New Zealand's changing demography will require a 'reinvention' of what it means to be a 'New Zealander' remains to be seen, although the nature of what constitutes a 'New Zealander' generally is a contested term (Liu, McCreanor, McIntosh and Teaiwa 2005) and not all New Zealanders, of whatever ethnic background, will understand and identify with being a New Zealander' in the same way. A personal identity, however that might be formed, does not necessarily translate into a national identity. The notion of a 'New Zealander' is a fluid and changing concept that breaks away from attempts to frame it in particular ways or within particular understandings. This has been demonstrated previously through the impact of the Maori renaissance on what constitutes a New Zealander and the impact of migration from the Pacific. Whether Asians in New Zealand will adopt a hyphenated identity (see Liu 2005) and whether New Zealand as a country positions itself internationally as an ally with Asia, or sees itself and its emerging significant Asian population as an indication that it is an 'Asian' country, remains to be seen.

Press releases, like those put out by New Zealand First in April 2008, play upon anxieties that the 'New Zealand' of the past and present will not be the 'New Zealand' of tomorrow. Asia:NZ made this point explicitly in the titling of a research report on Asians in Auckland: Diverse Auckland - The Face of New Zealand in the Twenty-First Century? (Friesen 2008). There are already questions emerging as to what it means to be an 'Asian New Zealander' in the form of the annual 'Banana' conferences, held by Asian New Zealanders who self-describe as 'bananas' (yellow on the outside and white on the inside) and discuss what it means to be an 'Asian New Zealander'. A city like Auckland faces its Asian 'ethnoscapes' every day (Friesen 2008).

Issues of who is a New Zealander are hardly unique to the twentieth and twenty-first centuries. The Chinese communities that migrated to New Zealand in search of gold and a better lifestyle were definitely treated as not New Zealanders (Ip 1996) and the levels of discrimination that are still recorded against Asian migrants would indicate that there are continuing levels of exclusion. As Pearson (2001:16) notes: 
To name oneself a New Zealander now, in contrast to past eras, is more likely to be a statement of being not British.... Nationality, 'race' and ethnicity are not natural categories or predetermined identities, they are political constructs with shifting memberships and meanings. They are ways of naming oneself and others, of representing identities and interests within different orders of collectivity.

This naming and representing of what it means to be a New Zealander may be seen in the new and controversial category in the New Zealand Census in 2006 of 'New Zealander' as an ethnic group. Those 'New Zealanders' who were not comfortable, or did not identify with being a member of an 'Asian' or 'Pacific' or 'Maori' or 'European or Other' ethnic group, could label, name, represent themselves as being a 'New Zealander'. There are significant problems, technically and politically, with adding a new ethnic categorisation to the census questionnaire - it is very difficult to track movement and compare changes and measure trends in a category that was only 'invented' in 2007. Moreover, this is a 'national' category ('New Zealander' is a mark of nationality or even citizenship) inserted among ethnic options (e.g. Asian, Pacific, European).

The inclusion of this category by Statistics New Zealand, even in the face of great opposition by the research communities, might point to something larger than mere obstinacy. There is perhaps a drive to define 'New Zealander' apart from being Anglo-Celtic but that has yet to fully embrace what it means to include Pacific, Maori and Asian ethnicities and identities. It is debatable as to what extent this notion of a 'New Zealander' (however that is understood differently by different people) extends beyond urban New Zealand and into New Zealand's rural communities, which certainly contain far smaller Asian communities. The Asia:NZ survey suggests that perceptions of Asia are less warm in these regions of New Zealand (Colmar Brunton, 2007: 19).

This assumes that the social and demographic trajectory that New Zealand is on will continue; it assumes a growing diversification of New Zealand's population; more importantly, it possibly assumes willingness on the part of New Zealand's other populations, particularly Maori and European populations, to embrace this changing diversity. Fleras and Spoonley (1999: X-xi) consider:

An alternative national narrative and identity has re-emerged, and it provides the basis for forging a new settlement and for the redefinition of sovereignty, citizenship and state policies. This is a historic opportunity, although, as we will argue, its potential is unlikely to be realised because many will regard the notion of a shared sovereignty 
in a post-colonising state to be radical and unacceptable. Moreover, such a notion has significant implications for other ethnic groups and policies. What is the commitment and politics of the majority group, Pakeha, in such circumstances? What should be the policy on immigration, and how are the emerging new ethnicities of now mature minority ethnic communities such as Tagata Pasifika going to be expressed and acknowledged in this new environment?

The impact on New Zealand's Maori population was a key point in New Zealand First's vitriolic response to the projected demographic statistics released in April 2008:

Mr Brown said he was particularly concerned that the Asian population threatened to eventually outnumber Maori. 'It's a bit rich when the original inhabitants get shoved further down the pile because successive governments keep throwing the doors open to New Zealand' (New Zealand First 2008:1).

Too easily and too often the debate around Asians in New Zealand slides into a debate about migration. The two are not mutually exclusive but they are not the same. Eliding the two issues perpetuates the notion that the Asian communities in New Zealand are wholly migrant communities. Domestic policy decisions around immigration or the labour market will affect New Zealand's current and future migrant populations.

We might also see migrants, and non-European ethnic New Zealanders being ostracised in the event of a significant economic slowdown, which has happened previously and could happen again (Gendall et al 2007). In times of economic prosperity, without the threat of job losses or competition from migrants in the workforce, New Zealanders are more likely to be more open about being 'multicultural' and warmer towards New Zealand's Asian populations (see Ward and Masgoret 2008). But New Zealand may be facing the end of the golden weather and changing economic times may be reflected in changing social perceptions.

As Gendall et al (2007:34) identify in their analysis of New Zealanders' attitudes to immigrants and immigration, 'given adverse economic conditions and associated negative socio-economic consequences, [this mix of attitudes] could again provide a platform for the type of anti-immigration politics and racism that occurred in the 1990s', and that these negative attitudes may be particularly strong in Auckland and among Maori. New Zealanders' percep- 
tions of Asia may be positively or negatively affected by the outcome of the Free Trade Agreement with China, signed in April 2008, or by the success or otherwise of the 2008 Beijing Olympics. If New Zealanders feel that they are losing out economically because of the trade agreement, then their negative attitudes toward China as a country may extend to the Chinese communities in New Zealand.

\section{CONCLUSION}

Will twenty-first century Aotearoa New Zealand be marked by new 'creative identities' among its diverse and multicultural population? Will Aotearoa New Zealand be a blend of Sione's Wedding, Scribe and the Lantern or Pasifika Festivals? Will the second- and third-generation of migrants to New Zealand forge for themselves a new hybrid of identity and, with it, a new hybrid identity for what constitutes a New Zealander? (Spoonley 2007; also Friesen 2008). Or will the manifestations of the Asian communities in New Zealand at least be more significant than just the ethnoscapes of temples, festivals and takeaways? At that superficial level of engagement, New Zealanders may be comfortable and warm towards Asians. But any level that requires the host communities to engage with its new Asian communities in ways that may be new and disrupting may find opposition and resistance. Integration may have support as long as it is one-way integration of migrants or trade or tourists, or non-European ethnic communities, into a European-New Zealand 'way of life' geographically, religiously, socially and educationally. But, where migrants cluster geographically (Friesen 2008), win most of the education prizes (Pang 2003) and bring in and practice religions that are not Christianity (De Souza 2007), then host communities may be less warm and welcoming toward Asians than what they indicated in Asia New Zealand's 2007 survey of their perceptions of Asia.

NOTES

1 Paul Spoonley provided incisive comments on an earlier draft of this paper; the two anonymous referees and Jacqui Leckie provided constructive peer review, while Antonia Kokalova-Gray provided useful editorial input.

2 Both the Ministry of Social Development and Statistics New Zealand are currently preparing policy reports on the effects and measurements of social cohesion while the Human Rights Commission has a Diversity Action Programme, established to 'celebrate diversity' in New Zealand, largely looking at New Zealand's different migrant and refugee populations. 
3 New Zealand First is a political party that sits on the 'right' of the political spectrum in New Zealand and has been the most vociferous of all New Zealand political parties against immigration from Asia to New Zealand.

4 The Asia New Zealand Foundation (Asia:NZ, formerly Asia 200o Foundation) was established in 1994 by the National government to promote New Zealanders' awareness of Asia and Asian peoples. Established by then Ministers of Foreign Affairs and Trade, Don McKinnon and Philip Burdon respectively, the Foundation emerged from a series of business seminars held in 1992. The increasing trade with the Asian region was a significant factor in the establishment of Asia 200o, but so was Burdon's conviction that New Zealanders had to develop deeper and more widely based understandings of Asian culture. Burdon was also concerned about, and spoke against, increasing levels of anti-Asian sentiment from those alarmed by increasing Asian (then, especially Japanese) investment in New Zealand, which was being portrayed by its opponents as a threat to the 'Kiwi' way of life (Bohan 2004).

5 From 2007, these regions were extended to include Africa. Australia was identified as a discrete region, whereas before it had been considered part of the 'South Pacific'.

6 Between these censuses there were some changes to questions and analysis. Changes in the ethnicity question used in the 1996 Census have resulted in some data that is not consistent between 1996 and 2001 or between 1996 and 2006. The ethnicity data for 1991 and 1996 has an output using up to three responses while the ethnicity data for 2001 and 2006 has an output using up to six responses.

7 All data for the figures is sourced from Statistics New Zealand

8 'Other' refers to people who do not identify with the other ethnic groups of European, Maori, Pacific Peoples, Asian, Middle Eastern/Latin American/African.

\section{REFERENCES}

Asia 2000 Foundation 2003 Tracking Study No. 5, Wellington: Asia 2000 Foundation.

Asia New Zealand Foundation 2006 Tracking Study No. 7, Wellington: Asia New Zealand Foundation. 
Basanayake, A. 1999 Employment Experiences of Sri Lankan Migrants in New Zealand, Auckland: Equal Employment Opportunities Trust.

Beal, T. 2006 'Coming to Terms with Trade: Exploring the Implications of New Zealand's Economic Relationship with Asia' in H. Johnson and B. Moloughney (eds) Asia in the Making of New Zealand, Auckland: Auckland University Press: 94-121.

Bedford R. and E. Ho 2008 Asians in New Zealand: Implications of a Changing Demography, Wellington: Asia New Zealand Foundation.

Bohan, E. 2004 Burdon: A Man of our Time, Christchurch: Hazard Press.

Boyer, T. 1996 Problems in Paradise: Taiwanese Immigrants in Auckland, New Zealand, Asia Pacific Viewpoint, 37 (1):59-79.

Butcher, A., P. Spoonley and A. Trlin 2006 Being Accepted: The Experience of Discrimination and Social Exclusion by Immigrants and Refugees in New Zealand, New Settlers Programme Occasional Publication No. 13, Palmerston North: New Settlers Programme, Massey University.

Callister, P., R. Didham and D. Potter 2005 Ethnic Intermarriage in New Zealand, Statistics New Zealand Working Paper, Wellington: Statistics New Zealand

Coddington, D. December, 2006 'Asian Angst: Is it Time to Send Some Back?', North and South: $38-47$

Colmar Brunton 2007 Perceptions of Asia, Wellington: Asia New Zealand Foundation.

Crawley, H. 2005 Evidence on Attitudes to Asylum and Immigration: What We Know, Don't Know and Need to Know, Working Paper No. 23, Centre on Migration, Policy and Society, University of Oxford, Oxford.

De Souza, R. (ed) 2007 'Faith for All: New Zealand's Growing Religious Diversity', AEN Journal 2 (2).

Favell, A. 2001 Philosophies of Integration: Immigration and the Idea of Citizenship in France and Britain, London: Macmillan. 
Fleras, A. and P. Spoonley 1999 Recalling Aotearoa: Indigenous Politics and Ethnic Relations in New Zealand Auckland: Oxford University Press.

Friesen, W. and M. Ip 1997 'New Chinese New Zealanders: Profile of a Transnational Community in Auckland', in W. Friesen, M. Ip, E. Ho, D. Bedford, and J. Goodwin (eds) East Asian New Zealanders: Research on New Migrants, Auckland: Asia Pacific Migration Research Network, Massey University Albany:13-19.

Friesen, W. 2008 Diverse Auckland: The Face of New Zealand in the Twenty-First Century? Wellington: Asia New Zealand Foundation.

Gendall, P., P. Spoonley and A. Trlin 2007 The Attitudes of New Zealanders to Immigrants and Immigration: 2003 and 2006 Compared, New Settlers Programme Occasional Publication No. 17, Palmerston North: New Settlers Programme, Massey University.

Henderson, A., A. Trlin and N. Watts 2001 'Squandered Skills? The Employment Problems of Skilled Chinese Immigrants in New Zealand', in R. Starr (ed.) Asian Nationalism in an Age of Globalization, Richmond: Curzon Press:106123.

Henderson, A. 2003 'Untapped Talents: The Employment and Settlement Experiences of Skilled Chinese in New Zealand', in M. Ip (ed) Unfolding History, Evolving Identity: The Chinese in New Zealand, Auckland: Auckland University Press:141-167

Henderson, A., A. Trlin, A. and N. Watts 2006 English Language Proficiency and the Recruitment and Employment of Professional Immigrants in New Zealand, New Settlers Programme Occasional Publication No. 11, Palmerston North: New Settlers Programme, Massey University.

Ho, E. and J. Lidgard 1998 'Give Us a Chance: Employment Experiences of New Settlers from East Asia', in P. Morrison (ed) Labour, Employment and Work in New Zealand, Proceedings of the Seventh Conference, 28th and 29th November 1996. Wellington: Victoria University of Wellington:126-132.

Ho, E., R. Bedford and J. Goodwin 1999 'Self Employment among Chinese Immigrants in New Zealand', in P. Morrison (ed.) Labour, Employment and Work in New Zealand, Proceedings of the Eighth Conference, 2oth and 21st November. Wellington: Victoria University of Wellington: 276-286. 
Ho, E., R. Bedford and C. Bedford 2000 Migrants in Their Family Contexts: Application of a Methodology, Population Studies Discussion Paper, No.34, Hamilton: University of Waikato.

Human Rights Commission 2003 Discrimination in New Zealand, Auckland: UMR Research.

Ip, M. 1996 Dragons on the Long White Cloud: The Making of Chinese New Zealanders, Auckland: Tandem Press.

Ip, M. 2003 'Preface' in M. Ip (ed.) Unfolding History, Evolving Identity: The Chinese in New Zealand, Auckland: Auckland University Press: xi-xvi.

Ip, M. and D. Pang 2005 'New Zealand Chinese Identity: Sojourners, Model Minority and Multiple Identities' in J. Liu, T. McCreanor, T. McIntosh and T. Teaiwa (eds) New Zealand identities: Departures and Destinations, Wellington: Victoria University Press: 174-190

Lal, S. 1998 An Exploration of how Indo Fijians have Reacted to Experiences of Racial Prejudice and Discrimination in New Zealand, unpublished MA Thesis, Auckland: University of Auckland.

Leckie, J. 1995 'South Asians: Old and New Migrations', in S. Grief (ed.) Immigration and National Identity in New Zealand, Palmerston North: Dunmore Press: 133-16o.

Leckie, J. 2007 Indian Settlers: The Story of a New Zealand South Asian Community, Dunedin: University of Otago Press.

Li, P.S. 2003 Destination Canada: Immigration Debates and Issues, Toronto: Oxford University Press.

Lidgard, J. 1996 East Asian Migration of Aotearoa/New Zealand: Perspectives of Some New Arrivals, Population Studies Discussion Paper No. 12, Hamilton: University of Waikato.

Lidgard, J. and H. Yoon 1999 'The Employment Experiences of Recent Korean Immigrants in New Zealand', in P. Morrison (ed.) Labour, Employment and Work in New Zealand: Proceedings of the Eighth Conference, 26th and 27th November, 1998, Wellington: Victoria University of Wellington: 263-275 
Liu, J. 2005 'New Zealand's Changing Attitudes Towards Asian Immigration, 1999-2004', Asian and Pacific Migration Journal, 14 (4):467-485.

Liu, J. McCreanor, T., T. McIntosh, T., and T. Teaiwa 2005 (eds) New Zealand Identities: Departures and Destinations, Wellington: Victoria University Press.

Moloughney, B. and J. Stenhouse 1999 "Drug-Besotten, Sin-Begotten Fiends of Filth': New Zealand and the Oriental Other,' New Zealand Journal of History, $33,(1): 43-64$

New Zealand First 2008, 'Figures confirm immigration folly'. Press release, 2 April 2008. Online at http://www.nzfirst.org.nz/content/display_item. php? $\mathrm{t}=\mathrm{o} \& \mathrm{i}=\mathbf{2 7 1 5}$

Pang, D. 2003 'Education, Politics and Chinese New Zealander Identities: The Case of the 1995 Epsom Normal Primary School's 'Residency Clause and English Test', in M. Ip (ed.) Unfolding History, Evolving Identity: The Chinese in New Zealand, Auckland: Auckland University Press: 236-257

Pearson, D. 2001 The Politics of Ethnicity in Settler Societies: States of Unease, London: Palgrave.

Spoonley, P. 1990 'Racism, Race Relations and the Media', in P. Spoonley and W. Hirsh (eds) Between the Lines. Racism and the New Zealand Media, Auckland: Heinemann Reid: 26-37.

Spoonley, P. and A. Trlin 2004 Immigrants, Immigration and the Media: Making Sense of Multicultural New Zealand, Palmerston North: New Settlers Programme Massey University.

Spoonley, P., R. Peace, A. Butcher and D. O'Neill 2005 'Social Cohesion: A Policy and Indicator Framework for Assessing Immigrant and Host Outcomes', Social Policy Journal of New Zealand, 24: 85-110

Spoonley, P. 2007 'Diversity and Creative Identities in 21st Century Aotearoa', Presentation to Metropolis Plus Conference, 15 October 2007.

Spoonley, P., P. Gendall and A. Trlin 2007 Welcome to Our World: The Attitudes of New Zealanders to Immigrants and Immigration, New Settlers Programme Occasional Publication No. 14, Palmerston North: New Settlers Programme, Massey University. 
Statistics New Zealand, 2 April 2008 'Projections Indicate Increasing Ethnic Diversity', Press release. Wellington: Statistics New Zealand.

Trlin, A., A. Henderson, A. and R. Pernice 1998 'Asian Immigration, Public Attitudes and Immigration: Patterns and Responses in New Zealand', in E. Laquain, A. Laquain, and T. McGee (eds) The Silent Debate: Asian Immigration and Racism in Canada, Vancouver: Institute of Asian Research/University of British Columbia: 227-248

Vasil, R. and H-k. Yoon 1996 New Zealanders of Asian Origin, Wellington: Institute of Policy Studies, Victoria University of Wellington.

Vasta, E., 2007, Accommodating Diversity: Why Current Critiques of Multiculturalism Miss the Point' Working Paper No. 53, Centre on Migration, Policy and Society, Oxford: University of Oxford.

Ward, C., and A. M. Masgoret 2005 'Attitudes Toward Immigrants, Immigration and Immigration Policy', Invited presentation at the Foundation for Research, Science and Technology's End-users' Seminar on Migration, Wellington.

Ward, C., and A. M. Masgoret 2008, 'Attitudes toward Immigrants, Immigration and Multiculturalism in New Zealand: A Social Psychological Analysis', International Migration Journal, 42, (1): 227-248 